\title{
A Rare Pathology Mimicking the Gallstone: Heterotopic Pancreas in the Gallbladder
}

\author{
Murat F. Ferhatoglu ${ }^{1}$, Taner Kivilcim ${ }^{1}$, Abdulcabbar Kartal ${ }^{1}$, Ali I. Filiz ${ }^{1}$ \\ 1. General Surgery, Okan University Medical Faculty, Istanbul, TUR
}

Corresponding author: Murat F. Ferhatoglu, ferhatferhatoglu@yahoo.co.uk

\begin{abstract}
The placement of pancreatic tissue in an organ outside the pancreas is called pancreatic heterotopy. Heterotopic pancreatic (HP) tissue is frequently observed in the stomach and duodenum, while the gallbladder is an extremely rare localization. In this article, we present pancreatic heterotopy located in the gallbladder, a rarely observed embryologic anomaly, with the study of two cases and a review of the literature.
\end{abstract}

Categories: General Surgery

Keywords: cholecystopaty, gallbladder, heterotropic pancreas, ectopic pancreas

\section{Introduction}

Apart from normal pancreatic tissue or independently of ductus-vascular structures associated with the pancreas, the appearance of pancreatic tissue in another organ is termed pancreatic heterotopy. The first heterotopic pancreatic tissue was described in 1729 by Jean Schultz in the ileal diverticulum and, in 1859, two cases of histologically proven heterotopic pancreatic (HP) tissue were presented by Klob. The first HP case located in the gallbladder was presented by Otschkin in the beginning of the twentieth century [1]. When the literature was examined, it was seen that there are 34 case reports since 1916. In this article, we present pancreatic heterotopy located in the gallbladder, a rarely observed embryologic anomaly, with the study of two cases and a review of the literature.

\section{Case Presentation}

\section{Case 1}

A 48-year-old female patient presented to the surgery clinic with complaints of three years of epigastric pain, which had increased for the last six months, and nausea after eating fatty foods. A complete blood count revealed a white blood count of 9550 cells $/ \mathrm{mm}^{3}\left(4600-10200\right.$ cells $\left./ \mathrm{mm}^{3}\right)$ and a hematocrit level of $38 \%(40 \%-54 \%)$. Her electrolytes, liver function tests, blood urea nitrogen, and creatinine were normal. A 7mm polyp in the gallbladder was detected (Figure 1) in the abdominal ultrasonography of the patient with a normal physical examination and no known disease. The patient underwent a laparoscopic cholecystectomy and was discharged on the first postoperative day, uneventfully. A pathologic examination of the specimen revealed an 8-mm polyp (Figure 2), including mononuclear cell infiltration consistent with chronic cholecystitis, thickening in the gallbladder wall, fibrosis, and $6 \times 4 \mathrm{~mm}$ heterotopic pancreatic tissue located in the submucosal area of the fundus (Figure 3). No further complications occurred in the threemonth follow-up of the patient.

use, distribution, and reproduction in any medium, provided the original author and source are credited.

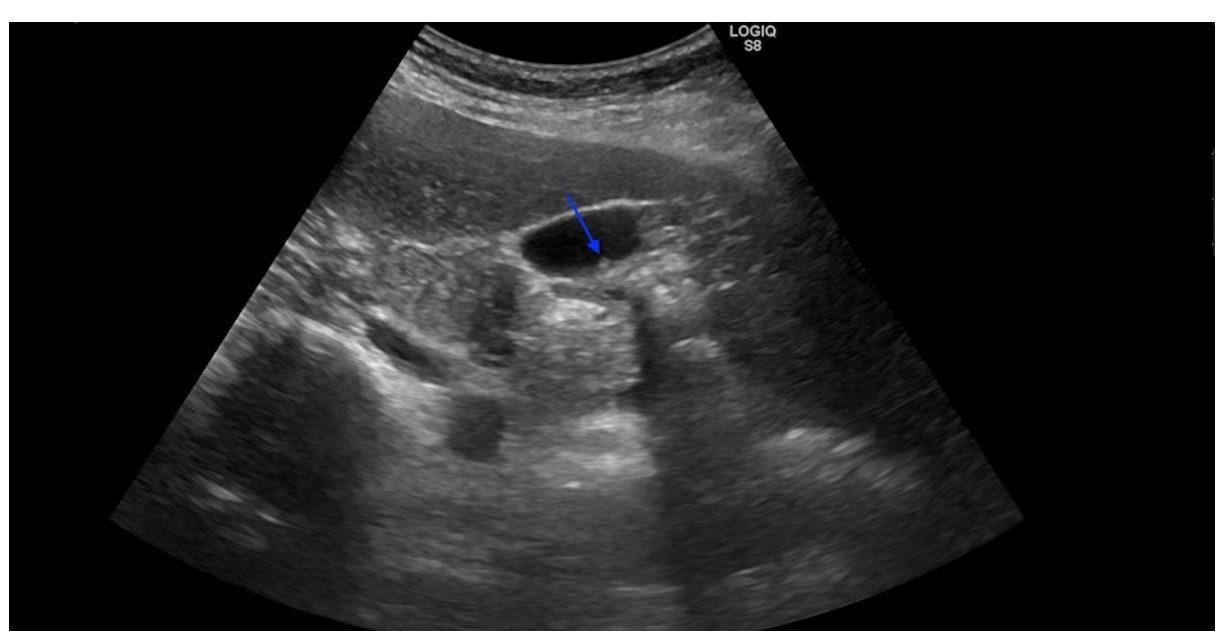




\section{Cureus}

\section{FIGURE 1: Ultrasonographic image of the polyp (blue arrow)}

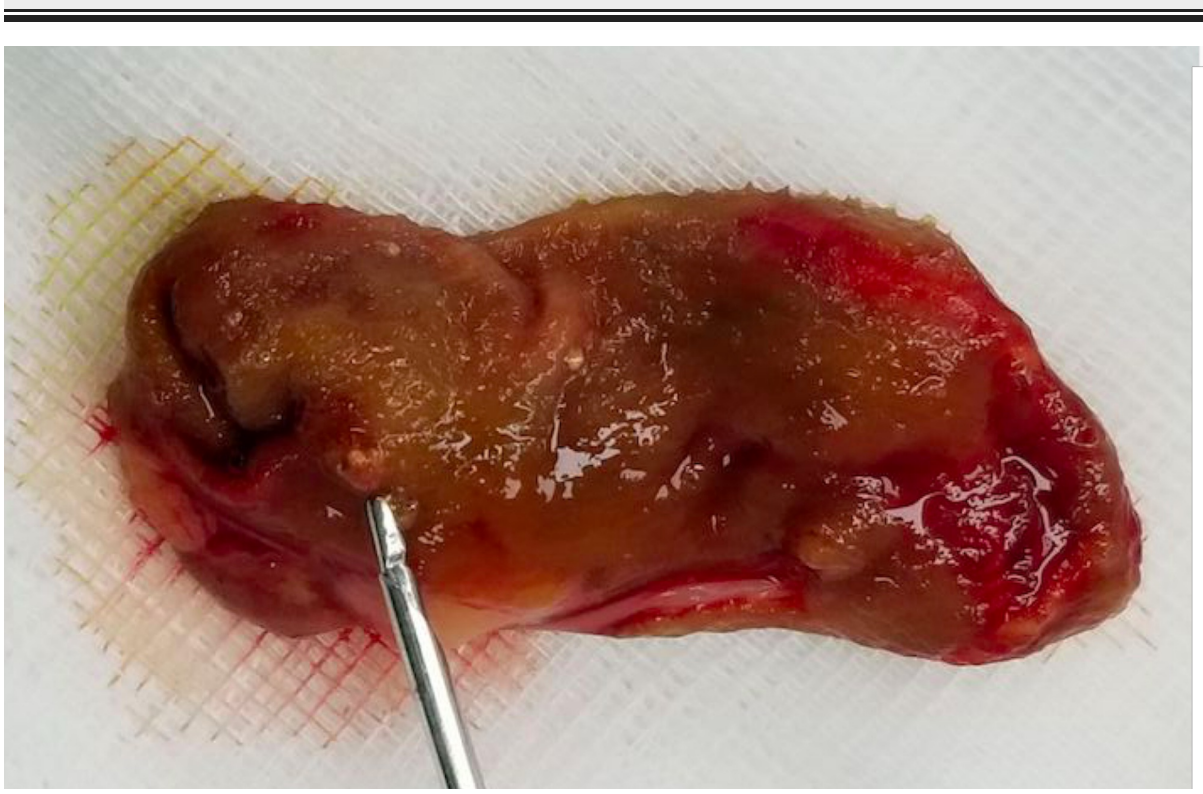

FIGURE 2: Needle shows a polyp in the gallbladder

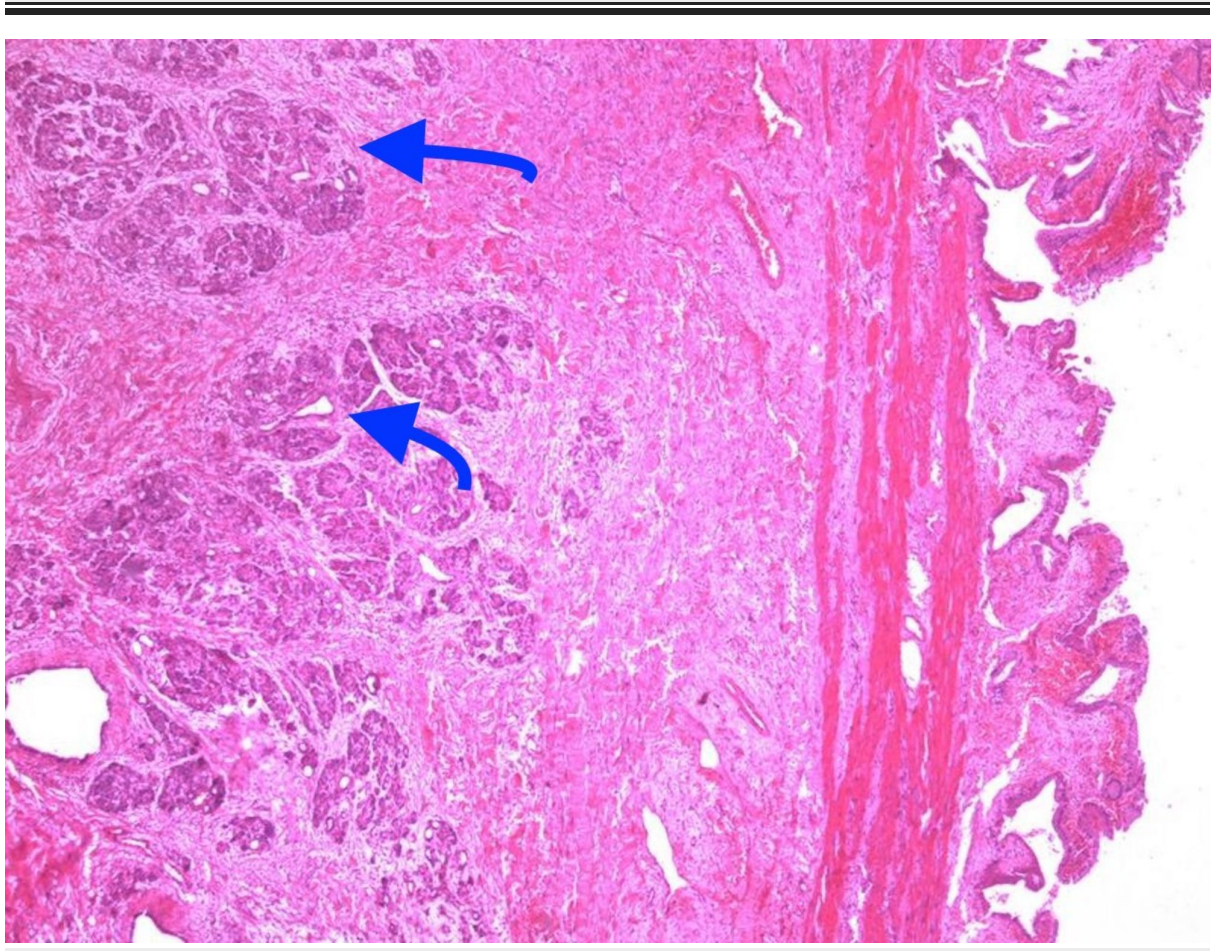

FIGURE 3: Heterotopic pancreatic tissue located in gallbladder (H\&E $\mathrm{x} 100)$

H\&E: hematoxylin and eosin

\section{Case 2}

A 39-year-old male patient presented to the surgery clinic with a one-year history of right upper quadrant pain. The complete blood count revealed a white blood count of 7200 cells $/ \mathrm{mm}^{3}\left(4600-10200\right.$ cells $/ \mathrm{mm}^{3}$ ) and a hematocrit level of $45 \%(40 \%-54 \%)$. His electrolytes, liver function tests, blood urea nitrogen, and creatinine were normal. A 6-mm polyp and sludge were detected within the gallbladder in the abdominal 


\section{Cureus}

ultrasonography of the patient (Figure 4) with a normal physical examination and no known disease. The patient underwent laparoscopic cholecystectomy and was discharged on the first postoperative day uneventfully. A pathologic examination revealed sludge, mononuclear cell infiltration consistent with chronic cholecystitis, thickening in the gallbladder wall, fibrosis, and 7-mm heterotopic pancreatic tissue in the gallbladder corpus (Figure 5). No further complications occurred in the three-month follow-up of the patient.

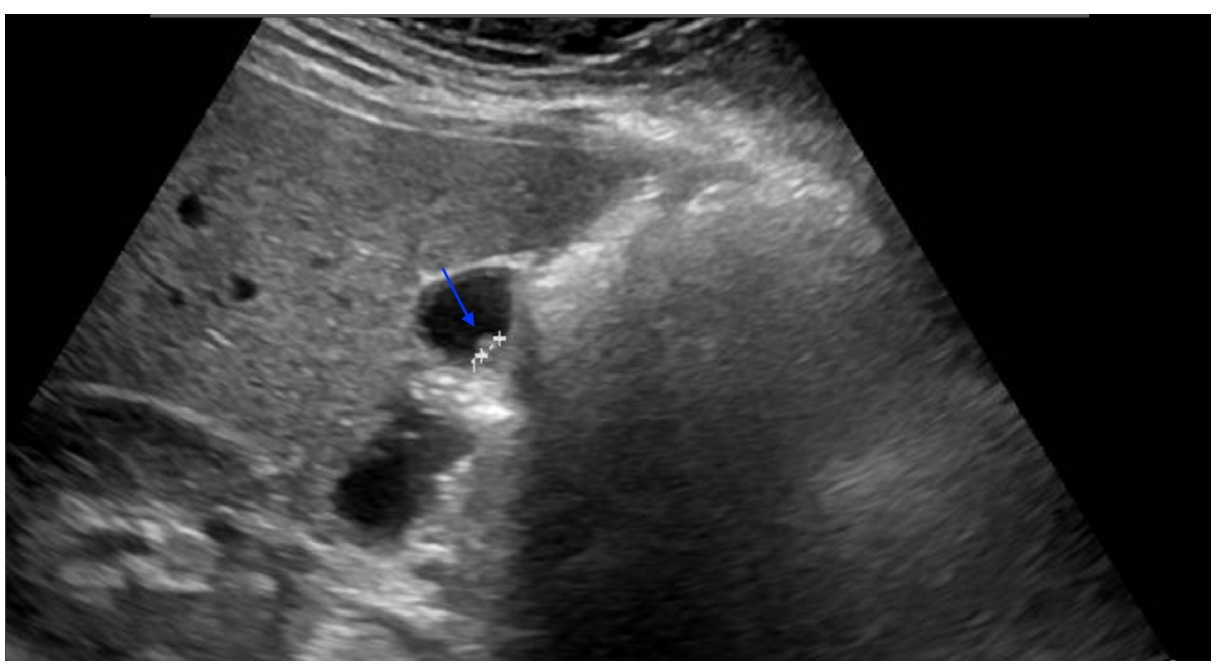

FIGURE 4: Ultrasonographic image of the polyp (blue arrow)

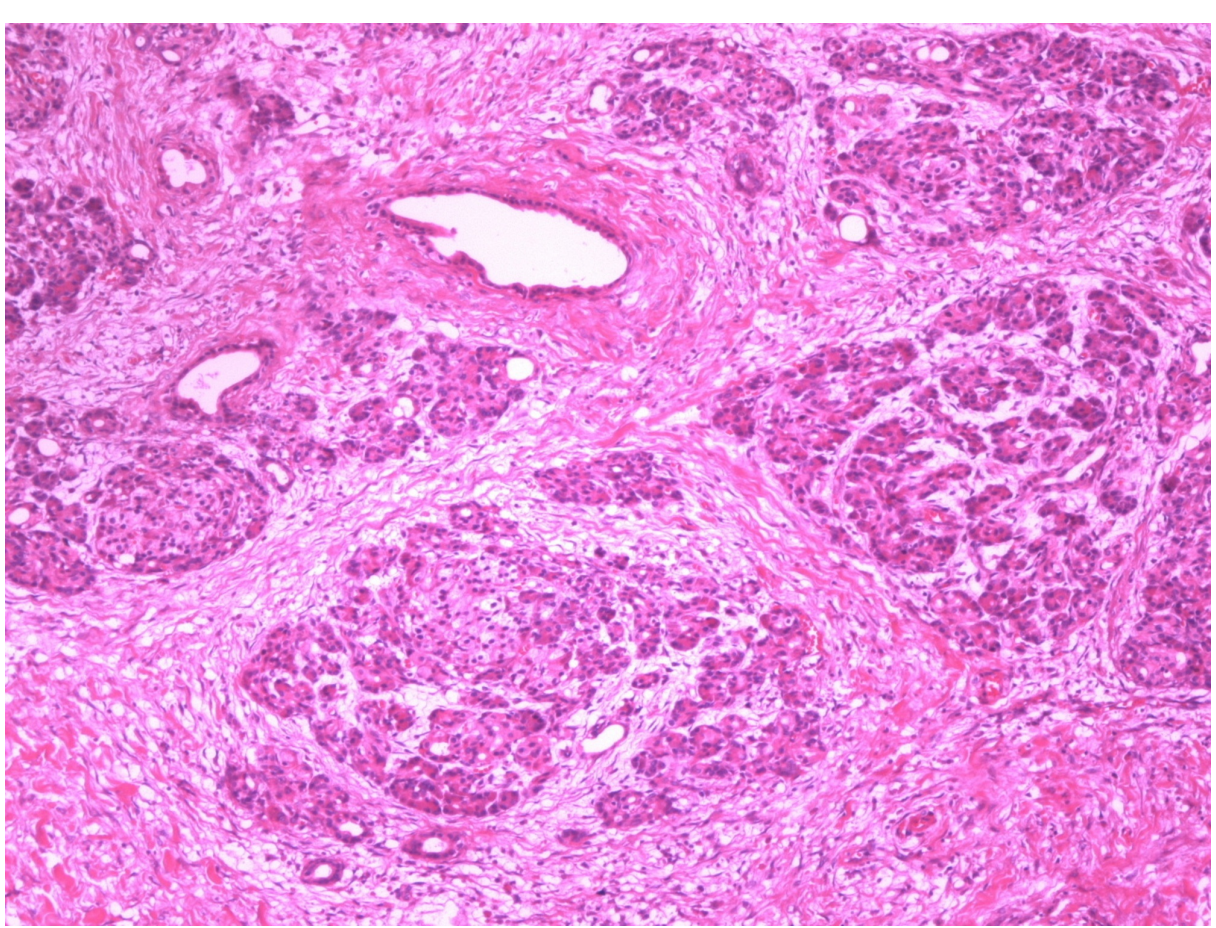

FIGURE 5: Heterotopic pancreatic tissue located in gallbladder (H\&E $\mathbf{x 1 0 0 )}$

H\&E: hematoxylin and eosin

\section{Discussion}

The heterotopic pancreatic tissue is often seen in the stomach, duodenum, and in the jejunum, Meckel's diverticulum, and mesentery [2]. The incidence of these embryological anomalies is up to $13 \%$ in postmortem studies, and the rate of detection after surgery is $0.2 \%$ [3]. Two hypotheses related to the 
formation of heterotopic pancreatic tissue have been proposed; the first hypothesis is that the heterotopic tissue is separated during the rotation of the primitive pancreatic tissue and the second hypothesis is that the ductal tissue belonging to the lateral bud during the development of the pancreatic duct is located abnormally in the embryological period [4].

Patients usually consult with non-specific symptoms, such as epigastric pain, abdominal distension, nausea, and vomiting. Symptoms are thought to be caused by enzymes released from ectopic pancreatic tissue [5]. When we reviewed 16 cases published in the English literature, eight of the 16 patients were operated on the diagnosis of gallbladder stones, three on polyps, and one on acute pancreatitis (Table 1). Both our cases were operated because of the cholecystopathic symptoms associated with the polyp.

\begin{tabular}{|c|c|c|c|c|c|c|}
\hline Author & Age (year) & Sex & Preoperative diagnosis & Location in gallbladder & Symptomatic & GBS \\
\hline Beltran et al. [6] & 8 & Male & GBS $^{*}$ & Body & + & + \\
\hline Beltran et al. [6] & 22 & Female & GBS $^{\star}$ & Neck & + & + \\
\hline Shiwani et al. [7] & 20 & Female & $\mathrm{GBS}^{\star}$ & Unknown & + & + \\
\hline Weppner et al. [8] & 26 & Female & $\mathrm{GBS}^{\star}$ & Neck & + & - \\
\hline Elpek et al. [9] & 40 & Male & Unknown & Neck & + & - \\
\hline Murakami et al. [10] & 49 & Female & Polyp & Unknown & - & - \\
\hline Kondi-Paphiti et al. [11] & 58 & Female & Polyp & Unknown & + & - \\
\hline Kondi-Paphiti et al. [11] & 48 & Female & GBS $^{\star}$ & Unknown & + & + \\
\hline Kondi-Paphiti et al. [11] & 53 & Female & Cancer & Unknown & + & + \\
\hline Sroczynski et al. [12] & 55 & Male & Acute pancreatitis & Unknown & + & + \\
\hline Basrur et al. [13] & 40 & Female & GBS $^{*}$ & Body & + & + \\
\hline Elhence et al. [14] & 18 & Female & GBS $^{*}$ & Neck & + & + \\
\hline Lee et al. [15] & 36 & Male & Adenomyomatosis & Duct & + & - \\
\hline Kalina et al. [16] & 43 & Female & GBS & Neck & + & + \\
\hline Klimis et al. [17] & 35 & Male & Polyp & Body & + & - \\
\hline Gucer et al. [18] & 80 & Male & Sludge & Body & + & - \\
\hline
\end{tabular}

TABLE 1: Pancreatic heterotopy cases located in the gallbladder

GBS: gallbladder stone

Heterotopic tissue is frequently localized in the neck and corpus section of the gallbladder, which can be explained by the fact that the lateral pancreas and corpus/neck of the gallbladder are more closely located during embryological development. In our cases, heterotopic tissue was located in the fundus and neck of the gallbladder. It is known that enzymes released from the tissue of the ectopic pancreas may cause neoplastic transformation, but there is no evidence of a gallbladder carcinoma case that has been proven to originate from a heterotopic pancreas in the literature. More extensive series of studies are needed to determine whether enzymes released from the ectopic tissue may cause carcinoma development or whether some of the gallbladder carcinomas are based on enzymes released from the ectopic tissue.

Preoperative radiological examinations are not successful in diagnosis. A definitive diagnosis is made after a histopathologic examination [5]. In our cases, gallbladder polyp and gallstones were detected in ultrasonography, and cholecystectomy was performed for patients having cholecystopathic symptoms.

\section{Conclusions}

Pancreatic heterotopy located in the gallbladder is an uncommon embryologic anomaly that is rarely seen and a preoperative diagnosis is impossible. This anomaly may cause cholecystopathic symptoms. All the patients presented in the English literature were diagnosed incidentally after cholecystectomy. Heterotopic 
pancreatic tissue is at risk of having a neoplastic transformation. Therefore, cholecystectomy in the presence of radiologically indicated polyps or nodules in patients with cholecystopathic symptoms without stones in the gallbladder may protect the patient from future cholecystitis, pancreatitis, and malignancy.

\section{Additional Information \\ Disclosures}

Human subjects: Consent was obtained by all participants in this study. Conflicts of interest: In compliance with the ICMJE uniform disclosure form, all authors declare the following: Payment/services info: All authors have declared that no financial support was received from any organization for the submitted work. Financial relationships: All authors have declared that they have no financial relationships at present or within the previous three years with any organizations that might have an interest in the submitted work. Other relationships: All authors have declared that there are no other relationships or activities that could appear to have influenced the submitted work.

\section{References}

1. Neupert G, Appel P, Braun S, Tonus C: Heterotopic pancreas in the gallbladder. Diagnosis, therapy and course of a rare developmental anomaly of the pancreas [Article in German]. Chirurg. 2007, 78:261-264. 10.1007/s00104-006-1203-6

2. Huang YC, Chen HM, Jan YY, Huang TL, Chen MF: Ectopic pancreas with gastric outlet obstruction: report of two cases and literature review. Chang Gung Med J. 2002, 25:485-490.

3. Mayes R, Mainie I, Davis R, Spence G: Pancreatic heterotopia presenting as a gastric submucosal lesion . Ulster Med J. 2010, 79:100-103.

4. Jovanovic I, Knezevic S, Micev M, Kristic M: EUS mini probes in diagnosis of cystic dystrophy of duodenal wall in heterotopic pancreas: a case report. World J Gastroenterol. 2004, 10:2609-2612. 10.3748/wig.v10.i17.2609

5. Sato A, Hashimoto M, Sasaki K, Matsuda M, Watanabe G: Elevation of pancreatic enzymes in gallbladder bile associated with heterotopic pancreas. A case report and review of the literature. J Pancreas. 2012, 13:235238. 10.6092/1590-8577/470

6. Beltran MA, Barria C: Heterotopic pancreas in the gallbladder: the importance of an uncommon condition . Pancreas. 2007, 34:488-491. 10.1097/MPA.0b013e31803816fc

7. Shiwani MH, Gosling J: Heterotopic pancreas of the gallbladder associated with chronic cholecystitis . JOP J Pancreas. 2008, 9:30-32.

8. Weppner JL, Wilson MR, Ricca R, Lucha PA Jr: Heterotopic pancreatic tissue obstructing the gallbladder neck: a case report. JOP J Pancreas. 2009, 10:532-534.

9. Elpek GO, Bozova S, Kupesiz GY, Ogus M: An unusual cause of cholecystitis: heterotopic pancreatic tissue in the gallbladder. World J Gastroenterol. 2007, 13:313-315.

10. Murakami M, Tsutsumi Y: Aberrant pancreatic tissue accompanied by heterotopic gastric mucosa in the gallbladder. J Pancreas. 1999, 49:580-582. 10.1046/j.1440-1827.1999.00905.x

11. Kondi-Paphiti A, Antoniou AG, Kotsis T, Polimeneas G: Aberrant pancreas in the gallbladder wall . Eur Radiol. 1997, 7:1064-1066. 10.1007/s003300050254

12. Sroczyński M, Sebastian M, Hałoń A, Rudnicki J, Sebastian A, Agrawal AK, Piekarz P: Pancreatic heterotopia in the gallbladder: an incidental finding after cholecystectomy. Folia Histochemica et Cytobiologica. 2013, 51:174-177.

13. Basrur GB, Utture SK, Deshpande AA: Heterotopic pancreas in the gallbladder. Indian J Surg. 2016, 78:429430. 10.1007/s12262-016-1561-3

14. Elhence P, Bansal R, Agrawal N: Heterotopic pancreas in gall bladder associated with chronic cholecystolithiasis. Int J Appl Basic Med Res. 2012, 2:142-143. 10.4103/2229-516X.106360

15. Lee SW, Yun SP, Seo HI: Heterotopic pancreas of the gallbladder associated with segmental adenomyomatosis of the gallbladder. J Korean Surg Soc. 2013, 84:309-311. 10.4174/jkss.2013.84.5.309

16. Kalina J, Michal W, Artur K, et al.: Heterotopic pancreas located in a gallbladder associated by cholelithiasis: case report. MEDtube Science Mar. 2015, 3:32-34.

17. Klimis T, Roukounakis N, Kafetzis I, Mouziouras V, Karantonis I, Andromanakos N: Heterotopic pancreas of the gallbladder associated with chronic cholecystitis and high levels of amylasuria. JOP J Pancreas. 2011, 9:458-460.

18. Gucer H, Bagci P, Coskunoglu EZ, Karadag C: Heterotopic pancreatic tissue located in the gallbladder wall. A case report. JOP J Pancreas. 2011, 12:152-154. 